\title{
Whole-Plant and Seed Bioassays for Resistance Confirmation
}

\author{
Nilda R. Burgos*
}

Key words: Dose-response assay, germination assay, petri plate assay, quick tests, seedling assay.

Much of agriculture-related research today involves weed resistance to herbicides. Resistance evolution is perhaps the strongest driver for the quest for new herbicide targets, novel weed intervention technologies, and the promotion of best management practices for sustainable crop production (Burgos et al., 2006; Norsworthy et al. 2012; Vencill et al. 2012). To date, 222 weedy species collectively have evolved resistance to 150 herbicides representing 21 sites of action (Heap 2014). For decades, scientists have developed numerous protocols for resistance confirmation using seeds, different plant parts, or whole plants. These have been reviewed by Beckie et al. (2000) and Burgos et al. (2013). We draw from these and other sources to present general guidelines for resistance confirmation that students and new researchers can use in planning their experiments. The most immediate questions that stakeholders seek to answer with resistance bioassays include:

1. Is the population resistant?

2. What is the level of resistance?

3. What alternative herbicides can be used?

Question 3 is for immediate management recommendations; thus, many resistance testing programs also test for sensitivity to alternative herbicides if a population is confirmed resistant. Close monitoring of weed populations and early detection of resistance can prevent long-term economic losses. Perhaps the first general guidelines for resistance confirmation were outlined by Moss (1999). This chapter presents generalized protocols for different approaches to confirming resistance to complement resistance-related topics in this special issue on Weed Science Research Methods. This section aims to help students and beginning researchers choose, modify, or design appropriate protocols for resistance testing to suit different situations. The procedures outlined here include

\footnotetext{
DOI: 10.1614/WS-D-14-00019.1

* Department of Crop, Soil, and Environmental Sciences, University of Arkansas, Fayetteville, AR 72704. Corresponding author's E-mail: nburgos@uark.edu
}

only bioassays that detect resistance regardless of the mechanism involved. Bioassays specific to target sites using biochemical techniques are discussed by Dayan et al. (2014). Molecular bioassays for target site-based mechanisms are discussed by Délye et al. (2014).

\section{General Procedure}

Collection of Samples. This activity is predicated on an observation of failed weed control that could not be attributed to environmental constraints, missed application timing, or herbicide application errors. Sampling for resistance confirmation generally pertains to seed collection. The critical questions that one should contemplate before sampling are:

1. Will plants be sampled individually or in bulk?

2. How many individual plants will be sampled; how many bulk samples, or how many plants will be collected to constitute the bulk sample?

3. What data are to be collected during sampling?

Step 1. Determine the Number of Samples and Quantity of Seeds To Be Collected. An appropriate procedure for collecting seeds from putative resistant $(\mathrm{R})$ plants for herbicide assays is critical. If the investigator wants to know plant-to-plant variation in resistance within a field, then individual samples should be collected (Hausman et al. 2011; Patzoldt et al. 2005). Otherwise, a bulk sample will suffice. To increase the power of detection of rare resistance alleles, a large number of samples is needed (e.g., 20 to 40 plants) (Burgos et al. 2013). For primarily inbreeding plants, genomic intermixing is minimal; thus, different morphotypes with different resistance traits could occur in the same field. A predominantly selfing species such as weedy rice (Oryza sativa L.), could have up to 15 different morphotypes in one field (personal observation). In such case, collect a large enough bulk sample of each morphotype (at least 5,000 seeds) to conduct the bioassays. For obligate outcrossing species such as Lolium spp. (Terrell 1968), only a few plants are needed to represent the population because of high 
intrapopulation genomic mixing. Thus, 5 to 10 plants are considered the minimum for crosspollinated species (Burgos et al. 2013). There are exceptions. Palmer amaranth (Amaranthus palmeri S. Wats.), for example, is an obligate outcrossing species that is highly morphologically diverse (Bond and Oliver 2006). In this case, one should strive to represent the diversity of morphotypes in the field. This dioecious species also has high intrapopulation diversity, with the lowest and highest genetic distance (GD) among plants within a population at 0.44 and 0.64 , respectively (Chandi et al. 2013). This is remarkably high considering the data was obtained from glyphosate-resistant populations, which have been homogenized by glyphosate selection. Individuals are more similar as GD approaches 0, or more diverse as GD approaches 1 (Nei 1973). The frequency of resistant offspring from each Palmer amaranth mother plant in a field varies widely (Burgos et al., unpublished data).

In cases with very few plants in the field (e.g., $<10$ ), collect seed from all plants. Do not collect samples from areas that are obviously missed by herbicide applicators, unless susceptible plants are also being sought.

Because survivors generally occur in patches, collect one bulk sample to represent a patch. Inspect the whole field and sample up to 10 patches to represent different sections of the field. This should allow one to draw a robust conclusion about the resistance status of such a field. The expected resistance frequency in a field can be inferred from bulk samples.

Step 2. Determine When To Collect Samples. Time the sample collection when the seeds are just starting to shatter. If possible, collect just the seeds that are easily dislodged from the inflorescence. Generally, these seeds are mature and would have high germination capacity. Seeds of many broadleaf species have to be collected as whole fruits or inflorescences.

Step 3. Determine What Extraneous Data To Collect During Sampling. Before field sampling, assess whether you need to collect supplemental information pertaining to the sample. This information falls in three general categories: (1) species traits, (2) species distribution and abundance, and (3) field history. Which data to collect depends on the research objectives. Plant traits (e.g., height, leaf size, branching pattern, growth habit, pubescence pattern, inflorescence morphology, fruit morpholo- gy, seed shattering habit) provide clues on ecotype differentiation or subspeciation, some of which could affect response to herbicides. This could in turn affect the interpretation of results. Notes on species composition, distribution, and abundance (Nkoa et al. 2014) inform us on general efficacy of weed control practice, the severity of the resistance problem, the possibility of multiple resistant species, or the long-term effect of management practices such as species shift. Field history is needed for firsttime exploration of a suspected problem or for population dynamics or evolution studies. This includes tillage, crop, and herbicide history for the last $5 \mathrm{yr}$ (including the current year) as much as possible (see Attachment $\mathrm{A}$ as an example). How much historical data end up being collected is a compromise between what is ideal to have and what can be obtained through farmers, consultants, extension agents, or public records. If the samples collected are resistant, but the field history does not indicate selection pressure, then it is possible that the resistant individuals were introduced from other locations by biotic (human activities, animals) or abiotic (wind or water movement) vectors.

Step 4. Record the Field Location. Denote a field ID to associate the sample with the location and record the GPS coordinates to enable a return to the site if needed.

Step 5. Plan for Logistics of Transport, Processing, and Storage of Samples. Seeds and accompanying plant tissues (panicles, some leaves, stems, fruits) may contain considerable amounts of moisture. Therefore, place freshly collected plant materials in paper sacks, cloth bags, or other containers that allow ventilation. Some species such as Amaranthus have inflorescences with a lot of green tissues at the time of sampling. Although the seedheads are placed in paper sacks, the samples respire, build up heat, and release moisture after several hours of being in a vehicle. As much as possible, minimize the time that samples are stacked in the vehicle. Unload the samples immediately on arrival at the research facility and arrange the samples in an area that is protected from the sun with free airflow. Extreme conditions will cause seeds to deteriorate or trigger deep dormancy (Bewley and Black 1994; Bewley et al. 2012).

Insects could be present in collected plant tissues. Drying the samples inside a glasshouse with ventilation turned off will kill insects. Alternatively, the collected tissues could be placed in a dryer at $60 \mathrm{C}$ 
FIELD HISTORY INFORMATION SHEET

(To accompany weed seed to be evaluated for herbicide resistance)

Date:

Producer:

Address:

Town: County: State: Zip:

Field ID and/or location:

Landmark:

GPS coordinate :

How long have you been farming on this location? years

How many acres are infested at this location? acres

What are the primary weed problems in this field?

What was the crop and herbicide program in this field in the current year and before?

Year Crop Herbicide Program

Contact person for sample:

Name:

Address:

Telephone:

E-mail:

Attachment A. Sample Field History Form.

for $3 \mathrm{~d}$ to desiccate all life stages of insects (eggs to adults) that may be in the plant samples.

Two weeks is usually enough for samples to air dry. Seed retrieval entails separating the seed from other plant materials, which may require using a mechanical thresher, followed by refined cleaning using a blower or gravitational separation of seed from chaff by agitation. In all these steps, take precautions to avoid cross-contamination of samples.
Contact person for analysis:

Name:

Address:

Telephone:

E-mail:
Seeds generally express innate dormancy upon physiological maturity or when dispersed from the mother plant; hence, they will not germinate unless subjected to a sufficient after-ripening period (Bewley et al. 2012). For example, barnyardgrass [Echinochloa crus-galli (L.) P. Beauv.] exhibits 5 to $50 \%$ germination capacity at maturity; the rest of seeds stay dormant for various lengths of time (Honek and Martinkova 1996; Kovach et al. 2010; Martinkova et al. 2006). Therefore, allow enough

154 - Weed Science 63, Special Issue 2015 
time for seeds to afterripen before conducting the bioassay by storing seeds at room temperature for at least a month. The optimum afterripening time differs among species and even among ecotypes within species (Kovach et al. 2010; Tseng et al. 2013). For example, the great majority of weedy rice should be afterripened for $90 \mathrm{~d}$ to obtain optimum germination; however, some reach $>90 \%$ germination within $30 \mathrm{~d}$ from harvest, and others need longer afterripening time beyond $90 \mathrm{~d}$ (Tseng et al. 2013). For long-term storage, seeds can be kept in a cold room with low relative humidity or in a freezer. Some general references about seed dormancy include Bewley et al. (2012) and Simpson (1990). It is necessary to search the literature for seed dormancy information about the species of interest before initiating seed or seedling bioassays.

Step 6. Test the Germination of Seed Samples and Break Dormancy if Needed. Good germination is important in resistance bioassays, especially for POST herbicides where efficacy is plant sizedependent. Temperature and light conditions for optimum germination are the most important factors to determine. These differ across species within the same genus and ecotypes within a species (Kovach et al. 2010; Tseng et al. 2013). In the genus Echinochloa, for example, the optimum germination temperature ranges from 25 to $30 \mathrm{C}$. Some require light to germinate; others require dark incubation (Kovach et al. 2010). If the light requirement is not met, the seed will not germinate. Therefore, conduct a germination test (under the right conditions) to determine how much seed needs to be planted to obtain the desired number of similar-size plants per treatment. First, if the germination requirements for the species of interest is already determined, check the literature. Besides temperature and light requirement, it is helpful to know, for instance, that Chinese sprangletop (Leptochloa chinensis L.) germinates best (80\%) when placed on the soil surface (Chauhan and Johnson 2008a). Without knowing this, the researcher would have covered the seed with some soil and fail to obtain good germination.

If needed, break seed dormancy to improve the uniformity of germination and germination capacity. Seed dormancy can be broken by afterripening, cold stratification, mechanical or chemical scarification, chemical treatments, heat treatment, exposure to alternating hot and cold temperatures, or a combination of these methods (Buhler and Hoffman 1999; Chauhan and Johnson 2008b, 2009;
Đikić et al. 2011; Karlsson et al. 2006; Martinkova et al. 2006; Tseng et al. 2013). Germination tests are generally conducted in Petri dishes lined with filter paper, with 50 to 100 seeds per plate replicated three or more times, moistened with up to $6 \mathrm{ml}$ of water, and incubated at the appropriate temperature and light conditions for 1 to 2 wk (e.g., see references cited in this section). Recalcitrant seeds may have to be pregerminated and then transplanted to the assay medium (Burke et al. 2006; Huan et al. 2011; Xu et al. 2010). Allocate time in your activity calendar for these potential preliminary experiments.

Classical Bioassay for Resistance Confirmation. This bioassay pertains to the traditional approach of planting seeds in pots and applying soil-applied herbicides either (1) preplant incorporated or (2) immediately after planting and POST herbicides at the recommended seedling size or growth stage. If testing for resistance to a particular herbicide for the first time, conduct a dose-response assay to determine the level of tolerance, and choose the discriminating dose for testing a large number of samples (Burgos et al. 2013).

Selecting a Standard Susceptible Population. It is imperative that a sample known to be susceptible to the herbicide in question is included in every run of a resistance bioassay. Levels of resistance can only be compared across populations if the same susceptible (S) standard is used in all bioassays. The selection of an $S$ standard is not always straightforward. It is ideal that the $S$ standard be collected from the same region from which the suspected $\mathrm{R}$ samples are collected. This is preferable over using a seed lot bought from commercial weed seed dealers from another region or another country. Many research groups use an $S$ standard not previously exposed to the herbicide (Burgos et al. 2013). However, these populations may be extremely sensitive to the herbicide and will result in artificially high resistance index values. In such cases, it is possible that a sample will register a high resistance index value, but can still be controlled by the full recommended dose. To survey the background tolerance of a species to a herbicide, test different $S$ populations and use one that represents the tolerance level of the majority.

When investigating a previously undocumented case of resistance in a species, obtain the putative $S$ population from an area proximal to the problem field, because populations from the same locality are 
expected to be more genetically similar than those from different regions; background genetic differences could affect plant response to herbicides.

Bioassay of Soil-Applied Herbicides. Step 1. Prepare the soil medium. To test PRE herbicides, use unsterilized field soil. As much as possible, this soil should represent the average or most common soil type in the region. Avoid soil of extreme $\mathrm{pH}$ or extreme organic matter content. Collect soil when it is friable and not cloddy nor hard. Spread the soil evenly on a flat surface to air dry. It may be necessary to pass the soil through a grinder to pulverize clods before putting it in the pots, because clods interfere with uniform distribution of herbicide on the soil surface.

Step 2. Determine the number of treatments, number of samples, replications, and experimental design. Consider manpower and space availability. For a preliminary dose-response assay of a suspected resistant sample, a seven-point titration consisting of three doses below and three doses above the full rate would a be good range, plus a nontreated check. Thus, for a putative $\mathrm{R}$ sample, the dose range could be: 0 , $0.125,0.25,0.5,1,2,4$, and 8 times the recommended field dose. For the $S$ standard, the dose range titration would be below the full rate, such as $0,0.0625,0.125$, $0.25,0.5,0.75,1$, and 2 times the recommended field dose. Another approach is to start with a log progression of doses to survey plant response over a wider scale (Kaundun et al. 2011) then conduct a follow-up assay to refine the dose range. The treatments should be replicated at least three times.

For a dose-response assay, the experimental units (pots) could be arranged in a split plot design with population (putative $\mathrm{R}$ and $\mathrm{S}$ ) as main plot and herbicide dose as subplot. This arrangement makes it easier to observe plant response to increasing herbicide dose when conducting visual evaluation. It also allows for immediate verification of potential outliers or errors in application, even before the scheduled evaluation period. Take care that the replications (blocks) are arranged to account for environmental gradients (e.g., temperature, light) where the plants are kept. One may also use a factorial arrangement of treatments.

If the discriminating dose has already been determined, then the experiment will consist of the $S$ standard and as many suspected samples as can fit in the facility. If an $\mathrm{R}$ population has already been identified, inclusion of an $\mathrm{R}$ standard (as positive check) is beneficial. The herbicide treat- ments will then consist only of the nontreated check and the discriminating dose. In this case, the experimental design can be factorial, but ensure that when conducting visual evaluation of herbicide activity, the treated plant is evaluated based on its nontreated counterpart. This entails sorting the pots into treated and nontreated pairs at the time of evaluation. If two or three doses are used in the resistance screening, plus the nontreated check, a split plot design may be an option with herbicide dose as main plot and population as subplot. This allows for better detection of interpopulation differences in response to each herbicide dose.

For large-scale testing, the discriminating dose may be the only rate that can be accommodated. What one considers as large population size differs between research facilities. Ultimately, the size of the experiment (population $\times$ doses) depends on the question the researcher wants to address and the resources. Useful information can be gained by adding a sublethal dose if space and manpower allow. This will reveal low-level resistance or differential tolerance among populations and will indicate relative propensities for evolution of resistance. On the other hand, one may be interested in knowing whether the weeds can tolerate a higher dose. Thus, some laboratories include 0.5 and 1 times, or 1 and 2 times the doses in their testing program (Burgos et al. 2013; Kaloumenos et al. 2011; Maneechote et al. 2005; Wise et al. 2009). Repeat the experiment to verify results.

Step 3. Choose the appropriate plant containers. Select the appropriate size of container for the number and size of seeds that will be planted. Spread the seeds uniformly and do not plant an excessive amount of seed beyond what is needed to achieve the desired plant population. Several studies have shown a negative correlation between the efficacy of herbicide dose and weed density (Baldoni et al. 2000; Kim et al. 2002; Lati et al. 2012; Oveisi et al. 2010). However, studies on optimum seeding rates that can be used without reducing herbicide efficacy are few or nonexistent for many species. Place the same amount of soil in each pot. Firm up the soil so that the soil level does not shrink upon watering.

Step 4. Planting. Decide ahead of time how many seeds to plant per pot. Twenty seeds per pot is generally sufficient, with four replications. Alternatively, one can plant 50 seeds in a tray with two replications. Plant the seeds at a uniform depth in all pots. This can be done by spreading the seeds on 
the firmed-up soil surface and covering the seeds with the same weight of soil across all pots to achieve the desired seeding depth.

Step 5. Irrigation. It is best to subirrigate the pots in order not to dislodge the planted seeds. Place the pots in a tray and fill the tray with enough water to soak the soil. Remove excess water and allow gravitational water to drain from the pots. The soil should be at field capacity (Veihmeyer and Hendrickson 1931) before applying the herbicide. Soil-active herbicides need to move to the zone of seed placement to be effective. Overhead irrigation would facilitate this process. Should overhead irrigation be used, choose a sprinkler head that delivers a gentle spray of water and use low water pressure.

Step 6. Calibrate the sprayer. Many laboratories are equipped with an indoor spray chamber with a motorized spray boom. Having an indoor sprayer allows one to spray with great precision. The spray boom can be adjusted to the proper distance from the target and not be subjected to human error throughout the course of application. Herbicide application can be done any time, as appropriate, without having to worry about wind speed or impending rain. However, herbicide application in a spray chamber takes more time than spraying outdoors because the platform can accommodate only a small number of pots at a time.

If an indoor motorized sprayer is not available, herbicides can be applied with a handheld boom. This entails arranging the pots to be sprayed outdoors and applying the herbicides in the same manner as treating field plots. Herbicide application in an outdoor setting is faster because there is minimal movement of pots. The plants are also exposed to natural lighting and temperature conditions up to the time when the plants have to be returned to the greenhouse. However, one has to consider weather conditions, the potential for drift, and potential human application error such as the variability and accuracy in walking speed and boom height.

To calibrate the sprayer, one needs to know the volume of herbicide solution $(\mathrm{ml})$ that should be delivered by the spray nozzle per unit time (min) to apply the desired herbicide spray volume (L) per unit area (ha). The following parameters are needed:

1. Target spray application volume. This ranges from 94 to $187 \mathrm{~L} \mathrm{ha}^{-1}$. Use the high range for soil-applied herbicides to achieve better distribution of herbicide on soil.
2. Speed of applicator. Laboratory sprayers can be run at $1.67 \mathrm{~km} \mathrm{~h}^{-1}$. If the herbicide is applied manually, walking speed could be between 3.34 and $5.01 \mathrm{~km} \mathrm{~h}^{-1}$.

3. Spray swath $(\mathrm{cm})$. This is the width of area effectively covered by the spray boom in one pass.

Calculate the expected spray delivery using the formula:

$$
\begin{aligned}
& \text { Sprayer discharge }\left(\mathrm{ml} \mathrm{min}^{-1}\right) \\
& =\text { Spray volume }\left(\mathrm{L} \mathrm{ha}^{-1}\right) \times \text { speed }\left(\mathrm{km} \mathrm{h}^{-1}\right) \\
& \times \text { swath }(\mathrm{cm})] / 60
\end{aligned}
$$

To determine whether the motorized sprayer is running at the desired speed (i.e., $1.67 \mathrm{~km} \mathrm{~h}^{-1}$ ), run the sprayer over a certain distance (i.e., $1 \mathrm{~m}$ ) and record the amount of time (s) it takes to cover that distance. Adjust the speed setting as needed. Use the actual speed of the sprayer in calculating the expected nozzle output. Calculate the spray delivery per nozzle by dividing the answer derived from Equation 1 by the number of nozzles. Run the sprayer for $15 \mathrm{~s}$, catch the spray output from each nozzle, and measure the volume. More information on sprayer calibration and related matters are available online in Spraying Systems catalogs such as the TeeJet ${ }^{\circledR}$ Spraying System (TeeJet Technologies, http:/www.teejet.com/english/home/tech-sup port/nozzle-technical-information.aspx). To achieve the desired sprayer output, changing the speed or nozzle size produces large changes in spray delivery. Adjustment of pressure achieves only small changes in spray delivery.

Step 7. Herbicide application. Apply the herbicide within $24 \mathrm{~h}$ of planting after the soil has been watered. Follow the recommended application volume. If applying multiple doses, apply the herbicide mixtures from the lowest to the highest dose. After herbicide application, place the pots sprayed with different herbicide doses in separate trays to avoid cross-contamination of herbicide concentrations in the process of subirrigation. Water the pots as needed.

Step 8. Monitor emergence period. Record the number of emerged seedlings in the nontreated pots at least once before the scheduled evaluation time of herbicide efficacy. In the absence of prior information, it is beneficial (but not necessary) to take emergence notes 7 and $14 \mathrm{~d}$ after planting. 
Recording emergence at different times will provide additional information regarding the germination behavior of the samples. It may take 3 or $4 \mathrm{wk}$ before a fair evaluation of herbicide efficacy can be done.

Step 9. Herbicide efficacy evaluation. At the appropriate termination date of the experiment, record the number of plants that are still alive, the level of injury, and the shoot biomass. Either fresh or dry biomass could be recorded.

Bioassay of Foliar-Applied Herbicides. Steps 1 to 3 are the same as in the bioassay of soil-applied herbicides. Note that commercial potting soil can be used for testing POST herbicides. In choosing the size of container, the ultimate goal is to avoid crowding and achieve uniform spray coverage of plants.

Step 4. Planting. Adjust the number of seeds to plant based on the germination capacity of the seed lot to obtain the number of uniform-sized seedlings desired per treatment. Seed lots could differ greatly in germination capacity. Therefore, conduct a germination test before conducting the bioassay. At the one-leaf stage (or earlier), thin the seedlings to the desired number. It is critical to do this as early as possible so seedlings can be extracted easily without damaging the roots of the remaining plant. Alternatively, seedlings could be cut at the soil surface. Grass shoots have to be cut below the soil surface to remove the meristem; otherwise, the shoot will regenerate within $2 \mathrm{~d}$.

Generally, five plants per pot with four replications, or 10 plants per pot with three replications is sufficient for a dose-response bioassay. The doseresponse assay informs us whether the plant is resistant and what the resistance level is, but not the frequency of resistance. To detect resistance frequency with high confidence (e.g., 95\% probability), a larger total number of seedlings (e.g., 100) need to be tested using a discriminating dose. This can be two replications of 50 seedlings per replication. The number of plants used in seedling bioassays varies widely (Burgos et al. 2013). The rule of thumb is to test enough plants per population to be confident in the test results and in making recommendations. If in doubt, consult a statistician.

Step 5. Irrigation. It is best to subirrigate the pots until the plants are large enough to withstand water pressure from overhead sprinklers. In doing this, keep plants that were sprayed with the same dose in one pan (for subirrigation) to prevent crosscontamination of treatments. When using volatile herbicides such as clomazone, 2,4-D, or dicamba, one may need to separate different populations, even if treated with the same dose, to avoid additional exposure.

\section{Step 6. Herbicide application. Apply POST} herbicides at the recommended growth stage using the recommended surfactants and additives. Allow at least $1 \mathrm{wk}$ from thinning before herbicide application so seedlings can recover from root disturbance before exposure to herbicide stress. Follow the recommended practices for POST herbicide application.

Step 7. Monitor emergence period. Follow the same principle as with PRE herbicides.

Step 8. Herbicide efficacy evaluation. At the appropriate termination date of the experiment, record the number of emerged plants that are still alive, the level of injury of live plants, and the shoot biomass. Evaluate fast-acting herbicides in 7 to $14 \mathrm{~d}$ after treatment (DAT) to observe maximum activity and then again at 28 to 30 DAT to observe any regrowth. Slow-acting herbicides can be evaluated within 3 and 4 wk after treatment (WAT).

Additional Note on Replication. In general, three to four replications are used in whole-plant bioassays (Burgos et al. 2013). In some cases, resistance screening tests could not be replicated because of space limitation. Nonreplicated bioassays are reliable only if a large number of plants (e.g., 100) are evaluated per population (Dickson et al. 2011; Wise et al. 2009; Zheng et al. 2011). Even then, one is risking the possibility of losing data if an unfortunate event occurs that causes plants to perish. A better alternative is to plan the experiment size to accommodate two replications with 40 to 50 plants per replication (Dickson et al. 2011; Owen et al. 2012). Regardless of the approach, repeat the test.

Evaluation of Resistance Level. Utility of resistance level estimates. Determining resistance level is important to researchers because it informs us on the nature of mechanisms of resistance, which in turn can influence management strategies or result in novel weed management technologies. A recent example is the development of BioDirect ${ }^{\mathrm{TM}}$ technology (Monsanto 2014) based on the understanding of the mechanism of resistance to glyphosate in Palmer amaranth (Gaines et al. 2013). 
Dose range. A dose-response experiment serves not only to determine the discriminating dose for large-scale resistance testing as mentioned in the previous section, but also to evaluate the highest dose a population can tolerate and to obtain clues for the potential resistance mechanism(s). To generate a robust dose-response curve for a reliable estimate of resistance level, test a wide range of doses to define the asymptotic ends of the curve. Extend the low end of the range to cover the region with barely visible effect; similarly, extend the high end of the range to a point where no further response is observed. A proper dose range entails adjustment of the generalized range given in the bioassay section and adding closer intervals of doses as needed (Ritz et al. 2014).

A note about herbicides with built-in surfactants. Some herbicides are formulated with proprietary mixtures of additives that facilitate entry and transport within the plant to ensure optimum activity. One example is glyphosate. In such case, it is advisable to use the plain formulation of the herbicide (without the additives) and add the appropriate surfactant at a constant concentration when mixing the herbicide spray solution (Dickson et al. 2011; Legleiter and Bradley 2008; Salas et al. 2012). This eliminates the confounding effect of increasing concentration of surfactant as the herbicide concentration is increased.

Estimation of resistance level. The dose-response curve based on injury rating or biomass can be used to estimate the amount of herbicide that causes a certain level of growth inhibition (e.g., $\mathrm{GR}_{50}, \mathrm{GR}_{90}$ $[50 \%$ or $90 \%$ growth reduction relative to the nontreated check]). Mortality data can be used to estimate the amount of herbicide that will kill a certain proportion of the population, also known as lethal dose $\left(\mathrm{LD}_{x x}\right.$, e.g., $\left.\mathrm{LD}_{50}, \mathrm{LD}_{90}\right)$. These parameters are useful in predicting the rate of expansion or reduction of the resistant population. The R/S ratios of $\mathrm{LD}_{X X}$ or $\mathrm{GR}_{X X}$ values are used to compare the magnitude of resistance of different populations (Burgos et al. 2013). The magnitude of resistance informs us on potential resistance mechanisms. For example, three goosegrass (Eleusine indica L.) populations in Malaysia showed different levels of resistance to fluazifop, an inhibitor of acetyl coenzyme-A carboxylase (ACCase, EC 6.4.1.2) (Cha et al. 2014). Two populations had lower resistance levels $(\mathrm{R} / \mathrm{S}=62$ and 88$)$ attributed to an ACCase mutation, $\operatorname{Trp}_{2027}$ Cys. The third popula- tion harbored a different ACCase mutation, Asn ${ }_{2097}$ Asp, and was about twice as resistant (R/S $=150$ ) as the first two. Similarly, resistance level and fitness of $\mathrm{R}$ plants are affected by the nature of catalytic site mutation in the herbicide target, acetolactate synthase (ALS, EC 2.2.1.6) (Yu and Powles 2014). Very high resistance level is indicative not only of a strong target site mutation, but also of a highly effective nontarget site resistance mechanism or an accumulation of multiple resistance mechanisms. There is benefit in detecting low-level resistance because it is indicative of an impending problem. Information on resistance mechanisms are important to scientists because it advances our understanding of plant evolution and could be the basis for novel intervention strategies for resistance management and general weed management. On the other hand, growers are generally concerned only about resistance confirmation and how to control it in the immediate term to avoid economic losses.

Quick Assays for Testing Resistance. Because the classical seedling bioassay in pots takes about 2 mo to complete, quick assays have been developed. These assays have used whole plants, seeds, or seedlings in different growth media. In this section, some examples of quick assays are presented using the aforementioned materials, except those assays aimed at evaluating resistance specific to a mode of action, which is discussed by Dayan et al. (2014).

Rapid Whole-Plant Assay for POST-Applied Herbicides. This procedure allows one to confirm resistance in the current cropping season without having to plant seeds or deal with potential seed dormancy problems. Escapes from an early POST application can be tested, and an immediate corrective treatment could potentially be applied to control the resistant weeds in the current crop. A whole-plant quick test was developed specifically for rigid ryegrass (Lolium rigidum Gaudin) and blackgrass (Alopecurus myosuroides Huds.) by Boutsalis (2001). This entails collecting vegetative plant parts from the field, transplanting these into pots in the greenhouse, and spraying the regenerated transplants with the herbicide of interest. This generally pertains to plants that escaped a preplant or early POST application, but also applies to plants left in the field after crop harvest. Although the protocol is developed for grass, it has been adapted to some broadleaf species (Walsh et al. 2001). The general procedure follows.

$$
\text { Burgos: Resistance confirmation • }
$$


Step 1. Plant collection. Follow the same principle of sampling as discussed previously, except here, whole plants are collected. Plants in clumps that do not follow a pattern associated with harvesting, tillage, or herbicide application are good candidates for resistance testing. Collect enough samples to represent the distribution of escaped plants in the field. To have enough material to test, select healthy plants that can be divided into many transplants. Dig up individual plants, remove as much soil as possible, cut off most of the shoots, wrap the root portion in wet paper, and place in a sealed plastic bag to avoid desiccation.

Plants that are already reproductive could not be used for this assay, unless it is a species that can be cloned even when already flowering or bearing fruit. Grasses that are already starting to flower can still be collected as long as new tillers can be regenerated after the shoots are cut.

Step 2. Prepare plant sections for transplanting. Rinse the roots with tap water. Separate the tillers into as many sections as needed for the bioassay. For a quick resistance check, the treatments could include 0,1 , and 2 times of the recommended field dose, for at least two replications. Use up to four replications if the plant material allows. Cut the shoots from 2.5 to $5 \mathrm{~cm}$ and the roots from 0.5 to $3 \mathrm{~cm}$ and transplant each cutting into a separate a pot. Commercial potting medium or field soil can be used.

Step 3. Plant care. Keep the transplants well watered, but not waterlogged, unless it is a species that thrives in flooded soil. In the first week, water with a fertilizer solution to speed up the regeneration process. Provide supplemental lighting, such as halide lamps, to improve the light intensity in the greenhouse. This will accelerate shoot regeneration and regrowth.

Step 4. Herbicide application. Allow the transplants to regenerate sufficient new tissues for herbicide application to be effective. Italian ryegrass (Lolium perenne ssp. multiflorum L.) takes at least 2 wk from transplanting to be ready for foliar herbicide treatment (Salas et al. 2012). Follow the recommended spray application volume and additives. Chlorsulfuron (ALS inhibitor); diclofop, fenoxaprop, fluazifop, haloxyfop, and sethoxydim (ACCase inhibitors); and isoproturon (photosystem II inhibitor) have been tested on cuttings of either blackgrass or rigid ryegrass and produced robust confirmation of resistance to these herbicides.
Clones of confirmed resistant tillering ryegrass have been used in dose-response assays and follow-up experiments (Salas et al. 2012).

If plants are sampled early in the cropping season, results can be used to recommend potential remedial herbicide application in the same season. Resistance detection is not affected by age of plants because regenerated plants respond similarly to seedlings (Boutsalis 2001).

Rapid Whole-Plant Assay for Root Growth Inhibitors. A variation of the above protocol was developed by Cutulle et al. (2009) for annual bluegrass (Poa annua L.) in hydroponics culture. The assay was developed for pendimethalin and prodiamine but could be adapted for other similar herbicides. This takes less time than the quick test for foliar herbicides but could be expensive to set up for large-scale testing. The general procedure follows.

Step 1. Calculate nutrients and herbicide for the liquid medium. For nutrient components, use the recipe by Hoagland and Arnon (1950) or more recent derivatives thereof. The nutrient solution composition may need optimization to suit the test species. Conduct a test run to calibrate the strength of nutrient solution to use. The normal concentration of micronutrients may be excessive for tiny plants. For example, rice seedlings grow best with just deionized water in the first week of establishment, then with half-strength nutrient solution starting in the second week (Sales et al. 2011). Stock solutions of the required nutrients can then be prepared accordingly.

Before making final calculations for herbicide amounts at different concentrations, conduct a test run using a susceptible standard. The full strength of herbicide mixture for field application may be too strong for the transplants in liquid culture. Calibrate the herbicide dose range to best reflect the expected plant response in the field.

Step 2. Prepare the culture containers and aeration system. Review the literature for the appropriate plant containers and aeration systems (Gibeaut et al. 1997; Resh 2012; Sales et al. 2011). Published literature abounds on hydroponics plant culture. For clones or seedlings, tubelike containers are sufficient. Setting up a hydroponics culture for the first time is more complex than preparing for a pot experiment. If plant response can be evaluated in about $1 \mathrm{wk}$, daily agitation of the nutrient solution may be sufficient. Conduct a test run. 
Step 3. Prepare the transplants and monitor plant response. Separate the tillers and cut the roots at a uniform length (e.g., 1 to $2 \mathrm{~cm}$ ) and suspend it in the nutrient solution. If using test tube containers, the plant could be held in place by a cotton ball. Another alternative could be styrofoam, cut to fit the inside diameter of the container, with an opening in the middle to fit the stem of the plant.

Step 4. Evaluate plant response. Measure root regeneration in $10 \mathrm{~d}$. A simple "yes" or "no" visual assessment of root regeneration could suffice to indicate resistance. Record other plant responses that are indicative of herbicide effect such as chlorosis (by visual rating, or using a chlorophyll meter [SPAD-502, Konica Minolta Sensing, Inc.]), number of new roots, or root and shoot length.

Seed Germination Assays in Agar Medium. The adoption of germination assays in petri dishes, paper towels, or other media that could be used on bench tops makes it possible to evaluate a large number of samples in less time than it would take to conduct the classical whole-plant assay. In Petri plate assays, putative $\mathrm{R}$ and $\mathrm{S}$ populations are also first tested with a wide range of doses to determine the discriminatory dose before conducting largescale resistance testing (Bourgeois et al. 1997; Kaundun et al. 2011). Bourgeois et al. (1997) used agar medium in a Petri dish assay to determine cross-resistance patterns of a large collection of wild oat (Avena fatua L.) accessions to ACCase inhibitors. Before embarking on this approach, learn the biology of the seed. The general procedure follows.

Step 1. Seed collection, cleaning, and storage. Follow the same principle as discussed previously.

Step 2. Conduct a germination test to determine the minimum number of seed to use per dish. This avoids waste of time and resources. Aim to have 10 seedlings per treatment per replication in the nontreated checks and adjust the number of seeds accordingly. This is difficult to do with fine-seeded species or with grass species such as Leptochloa spp., where it is difficult to distinguish between filled and empty florets.

Step 3. Determine the herbicide concentration to use in the assay. Conduct a dose-response assay first to determine the discriminating dose that will be used for testing a large number of samples. The range of concentrations will vary depending on the herbicide. For example, Bourgeois et al. (1997) used 11 concentrations within the 0 to $5-\mu \mathrm{mol}$ range for clodinafop and clethodim, and between 0 and $30 \mu \mathrm{mol}$ for tralkoxydim.

Step 4. Prepare the agar medium. The agar serves as an anchor for germinating seeds and a medium to dispense the herbicide and keep the seedling hydrated throughout the duration of the experiment. Anywhere from 0.25 to $1.3 \%(\mathrm{wt} / \mathrm{v})$ agarose can be used (Cirujeda et al. 2001; Kaundun et al. 2011; Kim et al. 2000; Letouze' and Gasquez 2000). A mixture with too little agar may not solidify; too much agar may solidify too quickly before the medium can be poured into the plates. Calculate the total volume of agar needed to fill the petri plates. First determine the water volume to fill each petri plate half-way and multiply by the total number of plates needed. Measure and mix the agar with water and melt this in a microwave. Cool the melted agar to about $50 \mathrm{C}$ and add the desired concentration of herbicide. The final herbicide concentration should be what is in the agar medium, not in the stock solution.

Step 5. Determine the discriminating dose from step 2. For large-scale testing, choose a concentration that consistently kills, or inhibits the growth of, all the $S$ seedlings, but not the $\mathrm{R}$ seedlings. This requires at least two repeats of the dose-response assay.

Step 6. Prepare the Petri plates and seeds. Pour the required volume of agar into the plates as soon as the target temperature stated above is reached. Otherwise, the agar mixture may solidify before all the mixture is poured onto the plates. Allow the agar to set at least overnight before placing the seeds in the plates. To shorten the waiting period, put the plates in the refrigerator.

Step 7. Incubate the plates for the desired germination period and conditions. Once the agar has solidified, place the desired number of seeds in each plate. Incubate for $7 \mathrm{~d}$ or longer, as needed. Many species will germinate at room temperature with light; others are light-sensitive, and others germinate best at cooler or warmer temperature. A germination chamber may be needed in cases where cool or warm temperature is required for germination, thus, the need to determine the optimum germination conditions before starting this assay.

Step 8. Evaluate seedling response. Measure the length of coleoptiles at the end of the incubation

Burgos: Resistance confirmation • 161 
period (7 to $14 \mathrm{~d}$ ). This assay was able to identify different types of resistance patterns of wild oat to ACCase inhibitors (Bourgeois et al. 1997). Type A has high resistance to aryloxyphenoxypropionate (AOPP) herbicides, but low or no resistance to cyclohexanedione (CHD) herbicides. Type $\mathrm{B}$ has low to moderate resistance to AOPP and $\mathrm{CHD}$ herbicides, whereas type $\mathrm{C}$ is highly resistant to all ACCase-inhibiting herbicides tested.

Petri Plate Assay Using Pregerminated Seeds. A slight variation of the above procedure is to incubate pregerminated seeds in Petri dishes lined with paper soaked in various concentrations of the herbicide in question. Measure the coleoptile length within 3 to $7 \mathrm{~d}$ of incubation. This has been used to test resistance to ACCase inhibitors in barnyardgrass (Huan et al. 2011), green foxtail (Setaria viridis L.) (Délye et al. 2002), and johnsongrass [Sorghum halepense (L.) Pers.] (Burke et al. 2006) and resistance to ALS inhibitors in flixweed [Descurainia sophia (L.) Webb ex Prantl] (Xu et al. 2010).

ELISA Plate Assay Using Pregerminated Seeds. Resistance to glyphosate in ryegrass can be detected by pregerminating seeds in petri dishes and transferring germinated seeds to enzyme-linked immunosorbent assay (ELISA) plates, filled with glyphosate solution of various concentrations (Ballot et al. 2009).

Step 1. Germinate a large number of seeds in a Petri dish lined with filter paper moistened with aqueous solution containing a fungicide to ward off fungal infection. Ballot et al. (2009) used $0.76 \mathrm{~g} \mathrm{~L}^{-1}$ iprodione in germinating ryegrass seed. Incubate the seeds under conditions optimum for its germination.

Step 2. After $2 \mathrm{~d}$, transfer the germinated seed into wells of ELISA plates filled with $150 \mu \mathrm{L}$ glyphosate solution in 12 concentrations ranging from 0 to $3,200 \mathrm{~g} \mathrm{~L}^{-1}$. Use a freshly prepared stock solution.

Step 3. Place the ELISA plates in transparent plastic boxes lined with moist paper with lid. For a cool-season weed such as ryegrass, incubate at $15 \mathrm{C}$ in a 16 -h photoperiod.

Step 4. After $7 \mathrm{~d}$, measure the coleoptile lengths.

The assay is completed in $16 \mathrm{~d}$. Results are tightly correlated $\left(R^{2}=0.95\right)$ with those of the classical assay.
Pregerminated Seed Assay in Perlite Medium. Perlite can be used as an alternative to liquid medium. Pregerminated seeds can be placed in pots filled with perlite medium and watered daily with nutrient solution with or without herbicide (Breccia et al. 2011). Place the pots in the greenhouse or growth chamber as appropriate. This method was developed to test sunflower (Helianthus annuus L.) resistance to imidazolinone herbicides, specifically imazapyr, at a dose range of up to $10 \mu \mathrm{M}$. In $2 \mathrm{wk}$, measure shoot and root lengths. This assay works with either soil- or foliar-active herbicides.

Agar-Based Seedling Assay. Kaundun et al. (2011) developed a resistance in-season quick (RISQ) test for detecting resistance to ACCase and ALS inhibitors among grass species, including blackgrass, green foxtail, phalaris (Phalaris paradoxa L.), ryegrass, and wild oat in agar medium. This was first developed for ACCase inhibitors clodinafop-propargyl and pinoxaden, and for the ALS inhibitor iodo-mesosulfuron. Use Petri plates that can accommodate seedlings of the test species. The goal is to detect resistance in a field infested with the problem species at the early seedling stage before the first application of a POST herbicide. This assay has been used in the Burgos laboratory to detect ryegrass resistance to pinoxaden in wheat fields. The general procedure follows.

Step 1. Seedling collection. Collect 15, 1- to 3-leaf seedlings from four sites in the field, making sure that roots are intact. Remove as much soil as possible and place each group of seedlings in a sealed plastic bag. Gently rinse the roots with tap water, wrap in wet paper towel, and place in a cooler for transport to the testing facility. This assay works with up to four-tiller ryegrass. Separate the tillers before plating and use just one tiller per plant.

Step 2. Preparation of reference populations. In anticipation of the time of sampling in the field, grow enough seedlings of the $S$ population in the greenhouse (or outdoors, if possible). If a known $\mathrm{R}$ population is available, include one in all of the assays. To ensure that the standard populations will be at the same growth stage as the seedlings collected from the field, plant a batch of the reference population(s) weekly.

Step 3. Agar preparation. Mix 0.5 to $0.8 \%$ (wt/v) agarose with water. Melt the agar in a microwave. Allow the agar to cool to about $50 \mathrm{C}$ and add the calculated amount of herbicide for each concentra- 
tion. Pour the agar into the Petri plates at a $1-\mathrm{cm}$ depth and allow to set at $4 \mathrm{C}$ for $24 \mathrm{~h}$ before placing the seedlings onto the medium.

Step 4. Determine the discriminating dose. Similar to the other bioassays, do this by conducting a dose-response assay. Finding the appropriate concentration range may take more trial runs in this medium than in the classical seedling assay. Replicate each treatment three times.

Step 5. Transplant seedlings onto the agar medium. Place four, soil-free seedlings into each plate, carefully positioning the plants so that the roots are firmly in contact with the agar. Place the lid on the Petri plate and seal it with parafilm to prevent the agar from desiccating.

Step 6. Incubation. Incubate the plates in the growth chamber or greenhouse with a 16-h photoperiod at 15 to $180 \mu \mathrm{mol} \mathrm{m} \mathrm{m}^{-2} \mathrm{~s}^{-1}$ light intensity and at an appropriate temperature. For ryegrass, the assay works best at 25/16 $\mathrm{C}$ day/night temperature. When conducting the assay for the first time, optimize the incubation conditions first.

Step 7. Evaluation. Treatments can be evaluated at 10 to $14 \mathrm{~d}$. At the end of the incubation period, $\mathrm{S}$ plants will either be dead or severely chlorotic and will have no root growth. On the other hand, R plants will remain mostly green, will develop a new leaf, and will have a lot of root growth. This assay determines the frequency of resistance, but not the level of resistance. However, one may also record injury and biomass data and determine whether these responses correlate well with herbicide dose.

If additional information is not collected, the resulting data will be frequency of resistant plants in the sampled field. The manufacturer, consultant, or extension agent can then decide whether the herbicide in question can still be recommended for that field. The farmer could also decide whether his management program can control the number of escapes expected from an application of the same herbicide.

\section{Parting Comments}

Classical seedling bioassay is still the most commonly used bioassay for testing resistance to herbicides. This is because it is the closest simulation to plants growing in the field. It also detects resistance regardless of the mechanism. The alternative, quick assays outlined here also detect resistance regardless of mechanism, but the growing conditions are "radically different." To have confidence in the results of these alternative bioassays, it is important to compare its diagnosis with that of the classical bioassay. If the alternative assay produces the same diagnosis as the classical assay, then the quick assay is best for testing a large number of samples in a short period. An effective resistance management strategy depends on proper field surveys, plant or seed sampling, seed storage, choice of assays, use of reference populations, and interpretation of test results.

\section{Literature Cited}

Baldoni G, Catizone P, Viggiani P (2000) Relationship between seed bank and actual weed flora as influenced by soil tillage and chemical control. Ital J Agron 4 (1):11-22

Ballot R, Deschomets G, Gauvrit C (2009) A quick test for glyphosate resistance in ryegrass. Pages 1-8 in 13th International Colloquium on Weed Biology. Dion, France: AFPP

Beckie HJ, Heap IM, Smeda RJ, Hall LM (2000) Screening for herbicide resistance in weeds. Weed Technol 14:428-445

Bewley JD, Black M (1994) Seeds: Physiology of Development and Germination. The Language of Science. New York: Plenum Press. 230 p

Bewley JD, Bradford K, Hilhorst H, Nonogaki H (2012) Seeds: Physiology of Development, Germination, and Dormancy, 3rd edn. New York: Springer. 391 p

Bond JA, Oliver LR (2006) Comparative growth of Palmer amaranth (Amaranthus palmeri) accessions. Weed Sci 54:121-126

Bourgeois L, Kenkel NC, Morrison IN (1997) Characterization of cross-resistance patterns in acetyl-CoA carboxylase inhibitor resistant wild oat (Avena fatua). Weed Sci 45:750-755

Boutsalis P (2001) Syngenta quick-test: a rapid whole-plant test for herbicide resistance. Weed Technol 15:257-263

Breccia G, Vega T, Nestares G, Mayor ML, Zorzoli R, Picardi L (2011) Rapid test for detection of imidazolinone resistance in sunflower (Helianthus annuus L.). Plant Breed 130:109-113

Buhler DD, Hoffman ML (1999) Andersen's guide to practical methods of propagating weeds and other plants. Lawrence, KS: Weed Science Society of America. $248 \mathrm{p}$

Burgos NR, Culpepper S, Dotray P, Kendig JA, Wilcut J, Nichols R (2006) Managing Herbicide Resistance in Cotton Cropping Systems. Cotton Inc Tech Bull for the Southern U.S. http://www.cottoninc.com/fiber/AgriculturalDisciplines/ Weed-Management/Herbicide-Resistance-Cotton-CroppingSystems/Managing-Herbicide-Resistance.pdf. Accessed: January 20, 2014

Burgos NR, Tranel PJ, Streibig JC, Davis VM, Shaner D, Norsworthy JK, Ritz C (2013) Review: confirmation of resistance to herbicides and evaluation of resistance levels. Weed Sci 61:4-20

Burke IC, Thomas WE, Burton JD, Spears JF, Wilcut JW (2006) A seedling assay to screen aryloxyphenoxypropionic acid and cyclohexanedione resistance in johnsongrass (Sorghum halepense). Weed Technol 20:950-955

Cha TS, Najihah MG, Sahid IB, Chuah TS (2014) Molecular basis for resistance to ACCase-inhibiting fluazifop in Eleusine indica from Malaysia. Pestic Biochem Physiol 111:7-13

Burgos: Resistance confirmation 163 
Chandi A, Milla-Lewis SR, Jordan DL, York AC, Burton JD, Zuleta MC, Whitaker JR, Culpepper AS (2013) Use of AFLP markers to assess genetic diversity in Palmer amaranth (Amaranthus palmeri) populations from North Carolina and Georgia. Weed Sci 61:136-145

Chauhan BA, Johnson DE (2008a) Germination ecology of Chinese sprangletop (Leptochloa chinensis) in the Philippines. Weed Sci 56:820-825

Chauhan BA, Johnson DE (2008b) Germination ecology of southern crabgrass (Digitaria ciliaris) and India crabgrass (Digitaria longiflora): two important weeds of rice in the tropics. Weed Sci 56:722-728

Chauhan BA, Johnson DE (2009) Seed germination and seedling emergence of synedrella (Synedrella nodiflora) in a tropical environment. Weed Sci 57:36-42

Cirujeda A, Recasens J, Taberner A (2001) A qualitative quicktest for detection of herbicide resistance to tribenuron-methyl in Papaver rhoeas. Weed Res 41:523-534

Cutulle MA, McElroy JS, Millwood RW, Sorochan JC, Stewart CN, Jr (2009) Selection of bioassay method influences detection of annual bluegrass resistance to mitotic-inhibiting herbicides. Crop Sci 49:1088-1095

Dayan FE, Owens DK, Corniani N, Silva FML, Watson SB, Howell J, Shaner DL (2015) Biochemical markers and enzyme assays for herbicide mode of action and resistance studies. Weed Sci 63:23-63

Délye C, Dohoux A, Pernin F, Riggins C, Tranel P (2015) Molecular mechanisms of weed resistance. Weed Sci 63:91-115

Délye C, Wang T, Darmency H (2002) An isoleucine substitution in chloroplastic acetyl-CoA carboxylase from green foxtail (Setaria viridis L. Beauv.) is responsible for resistance to the cyclohexanedione herbicide, sethoxydim. Planta 214:421-227

Dickson JW, Scott RC, Burgos NR, Salas RA, Smith KL (2011) Confirmation of glyphosate-resistant Italian ryegrass (Lolium perenne ssp. multiflorum) in Arkansas. Weed Technol 25:674-679

Đikić M, Gadţo D, Gavrić T, Šapčanin S, Podrug A (2011) Dormancy and weed seed germination. Herbologia 12:150-155

Gaines TA, Wright AA, Molin WT, Lorentz L, Riggins CW, Tranel PJ, Beffa R, Westra P, Powles SB (2013) Identification of genetic elements associated with EPSPS gene amplification. PLoS ONE 8:e65819 doi:10.1371/journal.pone.0065819

Gibeaut DM, Hulett J, Cramer GR, Seemann JR (1997) Maximal biomass of Arabidopsis thaliana using a simple, low maintenance hydroponic method and favorable environmental conditions. Plant Physiol 115:317-319

Hausman NE, Singh S, Tranel PJ, Riechers DE, Kaundun SS, Polge ND, Thomas DA, Hager AG (2011) Resistance to HPPD-inhibiting herbicides in a population of waterhemp (Amaranthus tuberculatus) from Illinois, United States. Pest Manag Sci 67:258-261

Heap I (2014) The International Survey of Herbicide Resistant Weeds. www.weedscience.org. Accessed January 16, 2014

Hoagland DR, Arnon DI (1950) The water-culture method for growing plants without soil. Journal circular. 2nd edn. Calif Agric Exp Stn 347:1-32

Honek A, Martinkova Z (1996) Geographic variation in seed dormancy among populations of Echinochloa crus-galli. Oecologia 108:419-423

Huan Z, Zhang H, Hou Z, Zhang S, Zhang Y, Liu W, Bi Y, Wang J (2011) Resistance level and metabolism of barnyardgrass (Echino- chloa crus-galli L. Beauv.) populations to quizalofop-P-ethyl in Heilongjiang province, China. Agric Sci China 10:1914-1922

Kaloumenos NS, Adamouli VN, Dordas CA, Eleftherohorinos IG (2011) Corn poppy (Papaver rhoeas) cross-resistance to ALS-inhibiting herbicides. Pest Manag Sci 67:574-585

Karlsson LM, Ericsson JAL, Milberg P (2006) Seed dormancy and germination in the summer annual Galeopsis speciosa. Weed Res 46:353-361

Kaundun SS, Hutchings H-J, Dale RP, Bailly GC, Glanfield P (2011) Syngenta 'RISQ' test: a novel in-season method for detecting resistance to post-emergence ACCase and ALS inhibitor herbicides in grass weeds. Weed Res 51:284-293

Kim DS, Brain P, Marshall EJP, Caseley JC (2002) Modeling herbicide dose and weed density effects on crop:weed competition. Weed Res 42 (1):1-13

Kim DS, Riches CR, Valverde BE (2000) Rapid detection of propanil and fenoxaprop resistance in Echinochloa colona. Weed Sci 48:695-700

Kovach DA, Widrlechner MP, Brenner DM (2010) Variation in seed dormancy in Echinochloa and the development of a standard protocol for testing. Seed Sci and Technol 38:559-571

Lati RN, Filin S, Eizenberg H (2012) Effect of tuber density and trifloxysulfuron application timing on purple nutsedge (Cyperus rotundus) control. Weed Sci 60:494-500

Legleiter TR, Bradley KW (2008) Glyphosate and multiple herbicide resistance in common waterhemp (Amaranthus rudis) populations from Missouri. Weed Sci 56:582-587

Letouze' A, Gasquez J (2000) A pollen test to detect ACCase target-site resistance within Alopecurus myosuroides populations. Weed Res 40:151-162

Maneechote C, Samanwong S, Zhang XQ, Powles SB (2005) Resistance to ACCase-inhibiting herbicides in sprangletop (Leptochloa chinensis). Weed Sci 53:290-295

Martinkova Z, Lukas J, Honek A (2006) Seed age and storage conditions influence germination of barnyardgrass (Echinochloa crus-galli). Weed Sci 54 (2):298-304

Monsanto. 2014. BioDirect ${ }^{\mathrm{TM}}$ Technology: An Agricultural Biological Platform. http://www.monsanto.com/products/pag es/biodirect-ag-biologicals.aspx. Accessed September 9, 2014.

Moss S (1999) Detecting herbicide resistance: guidelines for conducting diagnostic tests and interpreting results. Herbicide Resistance Action Committee (HRAC). http:/www.hracglobal. com/Education/DetectingHerbicideResistance.aspx. Accessed January 20, 2014

Nei M (1973) Analysis of gene diversity in subdivided populations. PNAS 70:3321-3323

Nkoa R, Owen MDK, Swanton CJ (2015) Weed abundance, distribution, diversity, and community analyses. Weed Sci 63:64-90

Norsworthy JK, Ward SM, Shaw DR, Llewellyn RS, Nichols RL, Webster TM, Bradley KW, Frisvold G, Powles SB, Burgos NR, Witt WW, Barrett M (2012) Reducing the risks of herbicide resistance: best management practices and recommendations. Weed Sci 60:31-62

Oveisi M, Mashhadi HR, Baghestani MA, Alizadeh H, Andujar JL (2010) Modeling herbicide dose effect and multiple weed species interference in corn. Pages 548-551 in Proceedings of the 3rd Iranian Weed Science Congress. Volume 1: Weed Biology and Ecophysiology. Babolsar, Iran: Iranian Society of Weed Science

Owen MJ, Goggin DE, Powles SB (2012) Non-target-site-based resistance to ALS-inhibiting herbicides in six Bromus rigidus

164 - Weed Science 63, Special Issue 2015 
populations from western Australian cropping fields. Pest Manag Sci 68:1077-1082

Patzoldt WL, Tranel PJ, Hager AG (2005) A waterhemp (Amaranthus tuberculatus) biotype with multiple resistance across three herbicide sites of action. Weed Sci 53:30-36

Resh HM (2012) Hydroponic Food Production: A Definitive Guidebook for the Advanced Home Gardener and the Commercial Hydroponic Grower. 7th edn. New York: CRC Press. 524 p

Ritz C, Kniss AR, Streibig JC (2015) Statistics in weed science. Weed Sci 63:166-187

Salas RA, Dayan FE, Pan Z, Watson SB, Dickson JW, Scott RC, Burgos NR (2012) EPSPS gene amplification in glyphosateresistant Italian ryegrass (Lolium perenne ssp. multiflorum) from Arkansas. Pest Manag Sci 68:1223-1230

Sales MA, Burgos NR, Shivrain VK, Murphy B, Gbur EE, Jr (2011) Morphological and physiological responses of weedy red rice (Oryza sativa L.) and cultivated rice $(O$. sativa) to $\mathrm{N}$ supply. Am J Plant Sci 2:569-577

Simpson GM (1990) Seed Dormancy in Grasses. New York: Cambridge University Press. 297 p

Terrell EE (1968) A Taxonomic Revision of the Genus Lolium. Washington, DC: U.S. Government Printing Office, U.S. Department of Agriculture Technical Bull. 1392. 2 p

Tseng TM, Burgos NR, Shivrain VK, Alcober EA, Mauromoustakos A (2013) Inter- and intrapopulation variation in dormancy of Oryza sativa (weedy red rice) and allelic variation in dormancy-linked loci. Weed Res 53:440-451
Veihmeyer FJ, Hendrickson AH (1931) The moisture equivalent as a measure of the field capacity of soils. Soil Sci 32:181-193

Vencill WK, Nichols RL, Webster TM, Soteres JK, MallorySmith C, Burgos NR, Johnson WG, McClelland MR (2012) Herbicide resistance: toward an understanding of resistance development and the impact of herbicide-resistant crops. Weed Sci 60:2-30

Walsh MJ. Duane RD, Powles SB (2001) High frequency of chlorsulfuron-resistant wild radish (Raphanus raphanistrum L.) populations across the western Australian wheatbelt. Weed Technol 15:199-203

Wise AM, Grey TL, Prostko EP, Vencill WK, Webster TM (2009) Establishing the geographical distribution and level of acetolactate synthase resistance of Palmer amaranth (Amaranthus palmeri) accessions in Georgia. Weed Technol 23:214220

Xu X, Wang GQ, Chen SL, Fan CQ, Li BH (2010) Confirmation of flixweed (Descurainia sophia) resistance to tribenuron-methyl using three different assay methods. Weed Sci 58:56-60

Yu Q, Powles SB (2014) Resistance to AHAS inhibitor herbicides: current understanding. Pest Manag Sci 70:13401350 DOI: $10.1002 / \mathrm{ps} .3710$

Zheng D, Kruger GR, Singh S, Davis VM, Tranel PJ, Wellerd SC, Johnson WG (2011) Cross-resistance of horseweed (Conyza canadensis) populations with three different ALS mutations. Pest Manag Sci 67:1486-1492

Received February 8, 2014, and approved June 19, 2014. 